\title{
Theorizing the Implications of Gender Order for Sustainable Forest Management
}

\author{
Jeji Varghese ${ }^{1}$ and Maureen G. Reed ${ }^{2}$ \\ ${ }^{1}$ Sociology and Anthropology, University of Guelph, Guelph, ON, Canada N1G 2W1 \\ ${ }^{2}$ School of Environment and Sustainability and Department of Geography and Planning, University of Saskatchewan, Saskatoon, \\ SK, Canada S7N $5 A 6$
}

Correspondence should be addressed to Jeji Varghese, varghese@uoguelph.ca

Received 1 August 2011; Accepted 2 October 2011

Academic Editor: I. B. Vertinsky

Copyright ( $) 2012$ J. Varghese and M. G. Reed. This is an open access article distributed under the Creative Commons Attribution License, which permits unrestricted use, distribution, and reproduction in any medium, provided the original work is properly cited.

Sustainable forest management is intended to draw attention to social, economic, and ecological dimensions. The social dimension, in particular, is intended to advance the effectiveness of institutions in accurately reflecting social values. Research demonstrates that while women bring distinctive interests and values to forest management issues, their nominal and effective participation is restricted by a gender order that marginalizes their interests and potential contributions. The purpose of this paper is to explain how gender order affects the attainment of sustainable forest management. We develop a theoretical discussion to explain how women's involvement in three different models for engagement—expert-based, stakeholder-based, and civic engagement—might be advanced or constrained. By conducting a meta-analysis of previous research conducted in Canada and internationally, we show how, in all three models, both nominal and effective participation of women is constrained by several factors including rules of entry, divisions of labour, social norms and perceptions and rules of practice, personal endowments and attributes, as well as organizational cultures. Regardless of the model for engagement, these factors are part of a masculine gender order that prevails in forestry and restricts opportunities for inclusive and sustainable forest management.

\section{Introduction}

In Canada, it can no longer be assumed that timber is the sole product of forestry. The broadening of interests in forests has been characterized by increased pressures from diverse interest groups to be involved in sustainable management of public resources. For example, forestry advisory committees across the country have been established to contribute directly into management decisions about forestry and thereby contribute local knowledge to the social, economic, and ecological dimensions of forest sustainability. Social sustainability includes consideration of society's responsibility, which is one of six criterion of sustainable forest management (SFM) in Canada. This criteria "addresses the effectiveness of institutions in managing resources in ways that accurately reflect social values, the responsiveness of institutions to change as social values change, how we deal with the special and unique needs of particular cultural and/or socio-economic communities, and the extent to which the allocation of our scarce resources can be considered to be fair and balanced (page 17 [1])". This social sustainability criterion includes fair and effective decision making (Criteria 6.4) and raises questions about inclusiveness, that is, how to ensure that a broad range of interests and values are included in these processes, given the heterogeneity of the population, particularly in terms of differences in terms of influence, dependency, and, crosscutting variables such as gender and ethnicity.

In this conceptual article, we identify three models of engagement in SFM-expert-based, stakeholder-based, and civic engagement-and consider the ways in which each model includes issues and concerns of one social group historically excluded from forestry management-women. This focus does not presuppose that women are the only or most important consideration for sustainable forest management. Nor does it suggest that all forestry issues are segregated by gender. Nevertheless, empirical research conducted in Canada, India, Sweden, Kenya, Nepal, and Thailand has suggested that the interests of women and men in forestry are 
significantly different and that these differences are typically not reflected in forest policy, see [2]. We suggest that the gap between interests and outcomes may arise because the forestry sector is subject to a "gender order" that privileges men's contributions to forestry, constrains women's participation in forestry management, and ultimately reduces the capacity of the forestry sector to achieve inclusive forestry management as a key component of social sustainability.

We begin our discussion by drawing on previous research that demonstrates that women bring distinctive interests and values to forestry issues. Next, we provide a brief discussion of gender order and inclusive engagement. The consideration of inclusive engagement hinges on conceptualizations of participation and representation. We consider different definitions and how they apply. We then define the different models for involvement-expert-based, stakeholderbased, and civic engagement. We consider, in theory, how women's involvement in each model might be advanced or constrained. We then analyze experiences of women under each model according to five criteria. Finally, we draw some conclusions on how the gender order of forestry affects opportunities for inclusive forest management.

1.1. Method/Approach. We approach this paper by conducting a meta-analysis of a range of empirical studies to illustrate key factors that limit women's involvement across a range of engagement options. We draw on research we have participated in across the country from the mid 1990's to the present as well as research conducted by other academics at Canadian universities and researchers at the Canadian Forest Service to examine expert and stakeholder models. For example, to examine expert models we focus on studies of women foresters in British Columbia, Alberta and Saskatchewan see [3-5]. To examine stakeholder models, we focus on research of Burns Lake and Revelstoke Community Forests in British Columbia see [6, 7], the Prince Albert Model Forest in Saskatchewan see [8], in-depth case studies of three public advisory committees in Alberta see [9] and two committees in Manitoba and Nova Scotia see [10] and a national survey of both members and chairpersons of forest advisory committees that was conducted by a network of social scientists in 2004 see $[11,12]$. To examine civic engagement models we draw mainly on published studies from outside of Canada, as this model is less prevalent within Canada.

\section{Rationale: Why Women's Voices Matter in Forestry Debates}

Despite the fact that most Canadian women do not use forest resources for subsistence purposes, they still hold interests and perspectives in forest management that are distinctive from men's and hence, their active involvement in giving advice about how forests should be managed could influence decisions about sustainability. Furthermore, forestry communities are experiencing rapid economic, social, and ecological changes that affect both women and men. At the community level, for example, climate change may have significant effects including reduced health status of residents during extreme events, altered paid and unpaid work patterns within communities, changes in livelihood and household relations, and long term health concerns for indigenous residents who have traditionally relied on country foods of the boreal forest. Because there remain marked differences in the roles, activities and expectations of men and women living in forestry-based communities, women and men will have different capacities to adapt to changing conditions [13].

Research has long documented that women express greater concern about the environment than men and express greater support for the protection of forest ecosystems [12-18]. They also typically express greater risk aversion to and concern for climate change-an environmental concern that will be significant for those living in boreal forests of Canada $[19,20]$. Additionally, in Sweden, researchers have observed that women perceive social impacts of forest management differently than men [21], while women employed in the USDA Forest Service are more likely than men to hold positive expectations and higher levels of trustworthiness regarding environmentalists, range users, citizen activists, and tribal representatives [22].

Yet, women have not mobilized these perspectives, and concerns into collective social or political actions affecting forestry directly. With respect to the environment, women have been found working in grassroots organizations [23], engaging more in environmentally friendly behaviors that can be integrated into their everyday life [24], and working actively with forest certification programs [25]. With respect to forestry, typically women are not leaders of forestry companies or national or international environmental organizations $[23,26,27]$ and they do not participate as actively in other decision-making positions to advance these interests [14].

Thus, while there is ample reason to believe that women bring different values, perspectives, expectations, and concerns to forestry issues, women have yet to advance these concerns directly. We suggest that this discrepancy can be explained by understanding how a particular gender order shapes ideas about what interests become represented in forest management forums. In the next section, we define gender order, describe how it operates within forestry communities, and illustrate how it shapes ideas and processes associated with inclusive forest management.

\section{Defining Key Concepts}

Our theoretical approach is taken from feminist scholarship on gender order, public involvement in environmental management, and inclusivity as a social indicator of sustainable forest management.

3.1. Theory on Gender Order. Theoretical work on gender order has focused on organizations and work sites. It is also applicable to "communities" in the sense of territorial and occupational communities related to forestry. A gender order refers to the "dichotomous order of gender whereby maleness and femaleness are perceived as opposites and attributed 
different forms of behavior, different roles, and different places (page 246 [28])". A gender order is not a natural order, but one that is created and recreated in everyday work interactions through organizational cultures that establish the normative rules, values, and meanings in the workplace. According to Gherardi and Poggio [28] these organizational cultures both establish and institutionalize gender positionings, frequently with the effect of "keeping women in "their place" (page 246 [28])".

That forestry work is highly gendered has long been documented. "Canadian forestry continues to be dominated by a masculine gender order that separates men and women and favours male workers in general... [whereby] potential contributions women might make to management and planning for the sustainability of forestry and forestry communities are overlooked (page 78 [29])". In North America and Scandinavia, forestry occupations have created and elevated the importance of a working man's culture or community [30-34]. This bias has been generated by the mystique of logging that created an image of forestry as hard, outdoor, physical labor that is dirty, dangerous, and ultimately masculine. Despite an increase in the range of forestry occupations in the late 20 th century that includes planning, regulation, as well as the introduction of labor saving devices, the idea of forestry as men's work still prevails. In forestry communities, this image is married to a traditional division of labor where men have "rightfully" enjoyed forestry jobs and high incomes and have served their families as primary breadwinners, while women have stayed at home to raise children or have only worked for "pin money" in forestry households. While this "traditional" (Traditional is set within quotations because of the debate over whether traditional refers to long-standing and prevalent gender roles or ones that are relatively recently instituted or locally naturalized [35].) division of labour has crumbled in urban settings, it has remained remarkably resilient in Canadian rural places [3]. For example, even where they are currently employed in "nontraditional" forestry occupations, women in forestry communities still carry the disproportionate share of juggling work-home schedules to meet childcare and other domestic duties $[5,36]$.

Furthermore, organizations, including advisory committees, model forests and other participatory venues, may be shaped by local practices, activities, norms, and attitudes that are taken for granted in everyday life. For example, in a study of Australian executive culture, Sinclair [37] described the organizational culture as a masculine domain "dominated by values, norms, symbols, and ways of operating that are oriented to men (page 6)" and that these characteristics were essential to the way men constructed their identity as leaders. The problem is "not that women's interests and men's interests are opposed-frequently they coincide-but rather it is to conduct their business as though they are always in synch (page 6)" [37]. Forest management operates within an organizational and occupational culture that is highly gendered. It has historically been biased toward male norms and thus can reproduce gender inequality even today-if unintentionally $[22,34,38,39]$. So even though women serve on advisory tables, as minority representatives, women are faced with male occupational and organizational cultures that shape the extent to which women's participation is effective. One might suppose that this is a reflection of a deeper structural gender order that permeates society, but other previously male-dominated fields (e.g., business, medicine, engineering) have made positive strides to being more inclusive of women [40] in a manner that is not currently reflected to the same degree within forestry.

This ordering of gender in the structure of forestry and forestry communities has become institutionalized as data used to describe the industry and forestry communities are limited, researchers typically do not segregate their findings on work-labor studies by gender, and government policy makers assume that forestry workers are male [29]. Together, these practices give the impression that women are not numerically, economically, or socially important to forestry, and consequently, women's potential contributions to management and planning for the sustainability of forestry and forestry communities are frequently overlooked. This pattern also affects decisions about when, how, and who to involve in sustainable forest management.

3.2. Inclusive Engagement. An enormous literature across a range of topic areas has dealt with public involvement in political and social life. Environmental management in general and forestry in particular are no exception. "Natural resource scholars and practitioners who are interested in public engagement often refer to concepts such as representation, participation, or involvement, whereas democratic theorists often refer to the term inclusion (page 533)" [41]. Our conception of inclusion is that it involves both "nominal" and "effective" participation.

Nominal participation refers to the simple demographic representation of particular groups in society. Representatives are assumed to share the values, attitudes, and socioeconomic characteristics of those they represent; in a sense, they are mirrors of the larger population $[42,43]$. Wellstead et al. [42] and Pitken [43] refer to this form of representation as descriptive or mirror representation. Participants may be seen as "standing for" the larger group. Applying this to forest management, if women are present in advisory committees, they are assumed to represent women's interests. This is a fairly limited and often inaccurate portrayal of how people actually operate. The limitation of nominal participation is that it tends to assume that individuals embody and represent a series of static characteristics rather than act on their beliefs. In the case of gender and forestry, a focus solely on nominal participation would assume that only women will bring forward concerns related to their gender and/or that women may restrict their contributions to such concerns. Despite their small numbers, we know that women come to decision making forums with knowledge and perspectives that are not necessarily relevant to gender (e.g., knowledge of the biophysical system), while they may have concerns about the topics of discussion or the procedures by which decisions are made that are different from those of their male counterparts.

Effective participation requires that participants are active and engaged in forest management. An assessment of effective participation would consider the rules of decision 
making, such as whether a process is viewed as accessible, transparent, fair, and consistent with existing laws, regulations, or policies $[8,44]$. It might also consider the attributes of individuals such as their knowledge of particular issues, their ability to mobilize resources, and their comfort in speaking out on particular issues. Thus, effective participation involves assessing the ability of members to enhance the equity and efficiency of decisions and to advance their goals.

Effective participation also gives consideration to how power operates within SFM processes and the influence of power on the capacity of individuals and groups to advance their interests $[3,6]$. Biases can be subtle, almost invisible, and yet, they can influence effective participation. They can emerge in procedures that determine selection criteria and processes, identify sources and relevance of data, value alternative experiences and knowledge, set the location and timing of meetings and payments for attendance, and provide level and type of agency support from government for the process $[45,46]$.

We suggest that nominal participation is linked to effective participation, particularly where participating groups are minorities. That is, the number of people from particular social groups will influence the "rules of entry" and "rules of practice" - both formal and informal—and thereby alter the conditions for effective participation. The absence of particular social groups may give rise to the assumption that the rules and procedures adopted by the more restricted group represents the "norm" against which any variation is considered deviant. Here, the notion of critical mass is relevant. For instance, Dahlerup [47] observed that among Scandinavian women politicians, once women became a significant minority (passing a threshold of some $30 \%$ seats in Parliament or local councils), there was less stereotyping and openly exclusionary practices by men, a less aggressive tone in discussions, a greater accommodation of family obligations in setting meeting times, and a greater weight given to women's concerns in policy formulation. The necessity of critical mass within forest advisory committees has also been documented more recently by Richardson et al. [10].

Effective participation may also be achieved through two forms of representation (subjective attached and objective unattached) noted by Pitken [43] and Wellstead et al. [42] whereby participants are "standing for" or viewed as acting on behalf of other groups. Subjective attached representation refers to acting for those with a subjective interest [43]. In the context of forestry, most advisory committees operate on this model; that is, participants are acting on behalf of others who share a stake in forestry matters. In the context of issues with a gender dimension, those with a subjective attached form of representation would be sensitive to gender issues and would acknowledge the differential stake that women may have in SFM. Hence, those perspectives would still be taken into account.

Objective unattached representation refers to acting for those who are uninterested [43]. This form of representation would involve individuals who might not be directly interested in forestry, but who might represent interests on behalf of all Canadians or even on behalf of the forest itself. Participants who speak for intrinsic values or future generations would fall into this category. With respect to gender, this form of representation would also imply that even if women were not present, there would be sensitivity to differences in perspectives by gender by those who participate. There is not much experience with this form of objective unattached representation in the Canadian forest sector. Value-based committees (with which we have little experience in Canada), citizen juries documented in the United States (again, little experience in Canada) or broader-based venues that are less engaged (e.g., open houses, questionnaire surveys, voting), and social science research (a few limited examples in Canada) may be seen as examples of attempts to achieve objective unattached representation.

Each of these forms of inclusion implies different ways in which gender-based issues are understood and brought to the table. Nominal participation/descriptive representation would require that women be present to ensure their interests are met, while subjective attached and objective unattached representation suggest that women need not necessarily be present. They do, however, require that on the part of participants there is an awareness of and an ability to understand and speak for the different perspectives that women and men may have.

\section{Inclusiveness of Expert-Based, Stakeholder-Based, and Civic Engagement Models}

Within this subsection, we examine three models of engagement for their extent of inclusiveness in SFM. To do this, we compare how the role of women across expert-based, stakeholder-based, and civic engagement models differ and examine factors that constrain women's access and effectiveness in each model.

The pyramid in Figure 1 illustrates fewer numbers of people involved in more elite models at the top and greater number of people involved as we move toward the bottom. Hence, by definition, the models at the top of the pyramid offer smaller degrees of inclusion of the range of views than do the models towards the bottom of the pyramid. Yet, the level of input is less detailed and less sustained as the scope of involvement widens. Nevertheless, in all three models, both nominal and effective participation of women may be constrained (or enhanced) by several factors including rules of entry, divisions of labour, social norms and perceptions and rules of practice, personal endowments and attributes, as well as organizational cultures.

These factors provide points of analysis or assessment of each of the three models described in more detail below. It is important to note that these factors act on different scales and can interact with each other. Rules of entry refer to how access is gained or constrained for nominal participation. Effective participation is enabled or constrained by the other factors. Division of labour considers how paid and unpaid work as well as specialization within paid work may be divided along gender lines. Social norms and perceptions and rules of practice include broader societal expectations about acceptable individual behavior within social settings as 


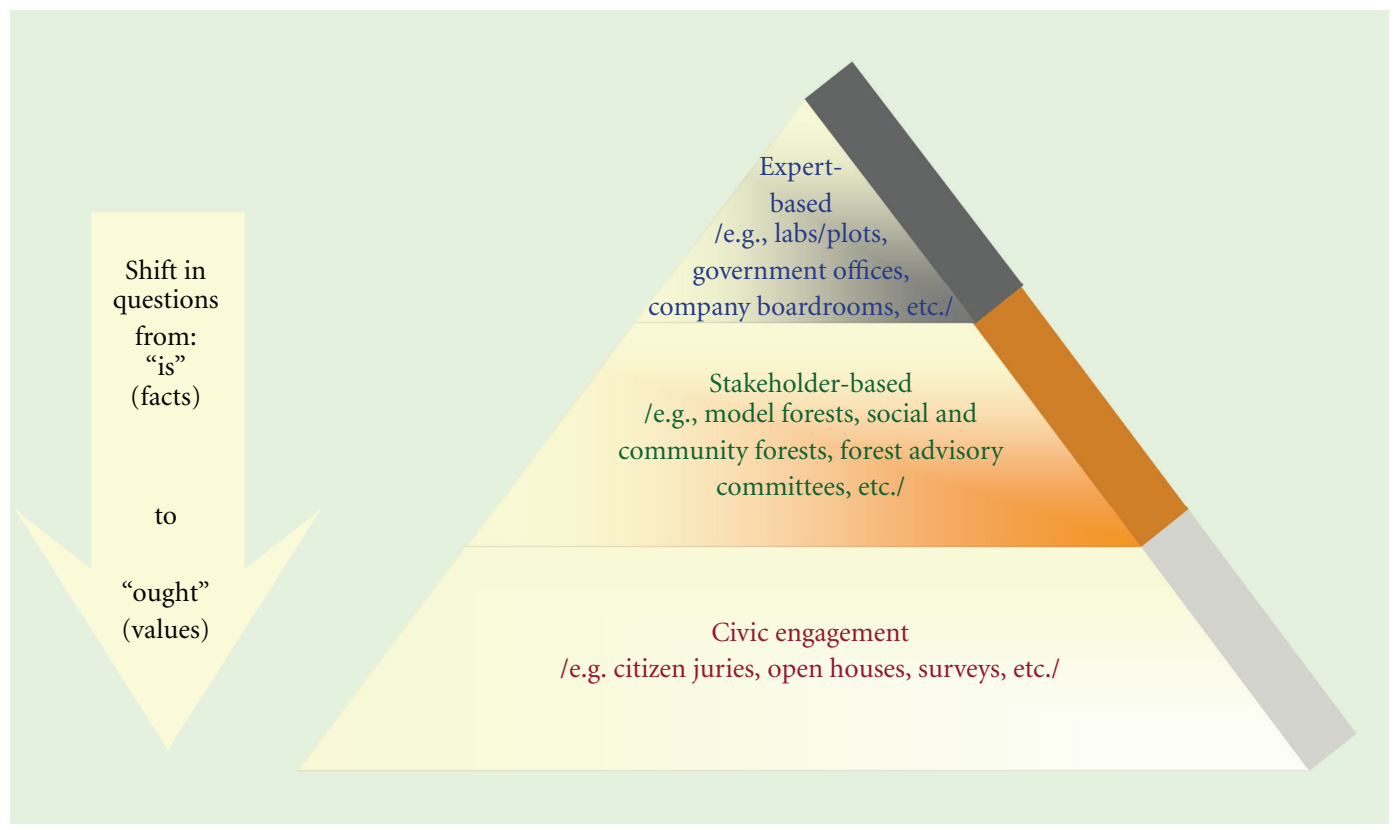

Figure 1: Three Models of SFM Engagement.

well as informal guidelines about how to behave collectively. Personal endowments and attributes include education level, property status, marital status, age, and so forth. Organizational culture refers to the shared values and norms that guide behavior within an organization and between the organization and others. We argue that regardless of the model for engagement, these factors are part of a masculine gender order that prevails in forestry.

4.1. Expert-Based Models of Engagement. Expert-based models provide representation and voice to experts (whether foresters, scientists, policy makers, etc.); thus privileging their knowledge in SFM. The underlying assumption within this model is that expert knowledge produces "facts," and that decision making needs to rely on these "objective facts" or "truths." In order to be involved in expert-based models of forest management, expertise is typically restricted to knowledge about forestry science, regulation or policy, and business. While decisions made about forestry affect forestry communities more broadly, it is rare that expertise is sought about the social dimensions of forestry communities, including public health, social welfare, culture, and so on that may be affected by changes in forestry or land use policy.

Rules of entry into expert panels require that participants have experience in positions of specific forestry expertise and/or authority. Very few experts in forestry science and business are women. For example, between 4 and 16 percent of registered professional foresters are female in each province [48]. Furthermore, Teske and Beedle [48] noted that in that year, there were no women Chief Executive Officers in any of the forest companies, although there were several women vice presidents. Despite increases in the number of women with formal education in Canada, women continue to be significantly underrepresented in management positions in the public and private sectors [5]. Thus, within expert-based models, the gendered division of labor and rules of entry typically restrict women's participation and reduce the range of issues deemed relevant to community sustainability. The lack of women in management positions within the industry and regulation of forestry translates directly into their absence in expert panels.

Gendered social norms and perceptions and associated rules of practice also influence expert-based models. There remains a social construction of appropriate female behavior (e.g., soft speech, deference to males, making the coffee) that operates even in the absence of overt structures. Even when entry rules are favourable, women may not participate as effectively due to a range of preexisting social norms that reinforce stereotypes about acceptable female behavior, appropriate ways of communicating, and social interaction between men and women. For example, female registered professional foresters (RPFs) working in BC in the 1990s reported being allowed to attend policy meetings to serve the coffee rather than to provide expertise [3].

4.2. Stakeholder-Based Models of Engagement. Stakeholderbased models give representation and voice to stakeholders, organizations/groups, and so forth that have a stake in forest management. In theory, stakeholder-based models are viewed as being more inclusive than expert-based models, in that they include local people and their knowledge. But of course this raises questions about who determines who has a stake and how groups may be represented? In terms of stakeholder-based models of engagement in Canada, such as within-community forests, model forests, and forest advisory committees, women have had a limited nominal and effective participation. In terms of nominal participation, for example, while 5 of 15 managers (staff) of model forests are 
female, only 2 of 15 model forest board chairs/presidents (decision makers) are female. In addition, few partner representatives within model forests and stakeholders are female. A case study of a community forest in British Columbia revealed no woman representative [6]. At a much broader scale, an analysis of 102 forest sector advisory committees across Canada revealed that women comprised only 17 percent of the membership [12]. These women held significantly different values about forestry and environmental protection than their male counterparts, they had lower levels of trust for industry, and they rated their experiences on the committee less favorably than men [12].

Formal rules of entry affect nominal participation within stakeholder models of engagement and may reinforce gender bias. Stakeholder representatives are typically selected as part of their employment or they may be selected if they are representatives of formal domains such as unions, management representatives, and chambers of commerce. Women are more likely to be part of organizations that address public health, education, children's sports, and community events that are not as hierarchically organized and/or are less likely to be considered part of "forestry." Men are more likely to be part of unions or business associations that are organized toward forestry employment are thus more likely to be considered stakeholders to represent local interests $[5,10$, 29]. Women that do attend are more likely to attend because of their work as ENGO representatives [12]. In addition, Richardson et al. [10] quoted one female member of a forest management advisory committee as saying "because we do not have a lot of women in the industry we do not naturally gravitate towards thinking about or suggesting women to be on the committee (page 527)." This quotation demonstrates that it becomes normalized to think that women are not interested or knowledgeable, and therefore, to overlook opportunities to engage women in these processes. Thus, while nominal participation may be constrained by a lack of women in professional networks of the forestry/resource sector, this gap gains positive reinforcement by prevailing assumptions about women's desire or ability to participate in stakeholder advisory groups.

Nominal and effective participation within stakeholder models of engagement are also affected by a gendered division of labour. Forestry as a profession is subdivided into a number of different area, some involves hard physical labour, in rough inaccessible terrain and remote areas and others in increasingly technical and office-related functions. This diversity of function, in combination with the socialization of men and women, has led to stereotypes about what type of work men and women in forestry prefer. As a result, certain aspects of forestry are seen as more suitable to males or females. Fullerton [49] and Martz et al. [5] found that even though on average women have higher levels of education than men, within the forest industry, women are overrepresented in clerical and administrative occupations and the ranks of unemployed, and that women are underrepresented in operations, scientific, and management categories. In a gender analysis of Alberta foresters, Varghese et al. [4] found that there was a perception of male domination in operations, whereas silviculture (which is considered to have less arduous fieldwork since it takes place in harvested areas) was perceived to be equally accessible to both men and women. Even within government positions related to forestry, women are overrepresented in clerical and administrative occupations and underrepresented in operations, scientific, and management categories [49]. In addition, the gendered division of labour in society continues to shape women's involvement in community and related service work. Despite stronger environmental sentiments, women are less able to be involved in direct activism or extra-curricular voluntary efforts because of the division of labour. Reproductive responsibilities limit the nature, scope, and efficacy of their activism or community work $[24,50]$. These responsibilities "not only structure one's disposable time, they also shape the costs and risks of movement participation (page 913)" [24]. Even where women are employed full-time, women, particularly young married women, tend to be more constrained by their family responsibilities. Thus, the timing of meetings and the need to balance other household/childcare work can be serious barriers to women's participation

Personal endowments and attributes can also shape expert women's contributions to forestry management. These factors include education levels, role of the family and in the community, and socioeconomic status. These personal attributes combine with social norms to provide entry points or barriers for some groups over others. For example, women living in rural areas typically have higher rates of formal education than men, but they have less formal employment experience in forestry. In a local culture where education-byapprenticeship is more highly valued, women's educational status may not grant them greater access to or effectiveness in forestry management processes. Richardson et al. [10] demonstrated how female members of forest management advisory committees were conscientious of their minority positions and felt uncomfortable offering their views on issues unless they were confident in their views.

Social norms and perceptions and rules of practice reinforce the division of labour and rules of entry. Related to the division of labour is a perception that women do not have a direct stake in forestry management or are not qualified to represent community interests. For example, women on Vancouver Island were shut out of some forestry activities and associated discussions because they were told that they "could not handle the language" [3]. If women were to participate, they may try to raise issues that are deemed irrelevant. For example, when women on Vancouver Island tried to engage men in discussions about local economic development, they were told that men in the community were not interested in participating in women's knitting circles. Richardson et al. [10] found masculine norms were taken for granted within forest management advisory committees. Many participants within her study felt that women on these advisory committees displayed behaviors typically attributed to men (e.g., being outspoken and confident) rather than behaviors typically attributed to women (e.g., shyness or drawing on emotional arguments).

These perceptions and practices reinforce and reproduce a masculine organizational culture that limits women's nominal and effective participation and reproduces gender 
inequality_if unintentionally. Gherardi [51] notes that even where masculine organizational cultures appear to include women, participants typically express their distrust of equality and implicitly threaten those who seek to change the rules. All of these challenges reduce the number and efficacy of women participants in stakeholder-based models that operate within highly masculinized cultures.

4.3. Civic Engagement Models of Engagement. Civic engagement models reflect more of an increased acknowledgement of the public nature of the bulk of forest resources and hence are based more on representing the diverse set of values that are present among the general public, not only the local communities. Civic engagement models however are not well developed in the Canadian forest sector, so we turn to examples in other jurisdictions. Citizen juries, which were originally developed in Europe [52, 53], have been used in the United States to incorporate the concerns of "ordinary citizens" in contested public debates [54].

Rules of entry. Generally, citizen juries are randomly selected with some consideration of balancing across selected characteristics such as age, education, and gender [53], however there are also examples where marginalised populations, such as women, are targeted [55]. However, in the latter case, this "process of selecting jurors may be contested-for example, those who do not feel it is important for women to participate directly (page 79 [56])" reflecting gendered social norms/perceptions and rules of practice impacting nominal participation.

Social norms/perceptions and rules of practice and organizational cultures can also diminish effective participation. As citizens' juries are modelled on an idealisation of the legal process [57] with an emphasis on expert testimony and rationalism [58], Ward et al. argue that it is "easy to be patronising, tolerating "non-rational" forms of argumentation from "others" (e.g., from women or indigenous groups), or as a second-best when rational argumentation fails (page 286 [59])" Pickard's [60] criticisms of citizen juries related to their lack of accountability, authority, legitimacy, and representativeness raises broader questions about the role of civic engagement in forestry management.

Other mechanisms that would involve a wide range of participants who speak for others include open houses, surveys, and workshops. Although people may speak on their own behalf, the commitment by each individual is less sustained and the input is less detailed than that of the other mechanisms. In addition, although women may secure nominal participation, effective participation is marred by the lack of influence of most civic engagement models [60].

Table 1 provides an overview of some types of measures that would enable us to assess women's nominal and effective participation for each form of representation within each model of engagement. Citizen engagement models also seem to share many of the drawbacks of stakeholder models. As we move from expert to civic models, we improve the chances for nominal participation of women because the criteria for selection become less specialized, however, none of the models addresses effective participation because the barriers are systemic, insomuch that the barriers are often invisible.
Table 2 highlights some examples of how the gender order pervades each of the three models of engagement. Women historically have been absent (lack of nominal participation) or present but effectively silenced (limited effective participation) in forestry management. In comparing engagement models, we see that there has been limited access and limited effective participation for women in all three models. We have shown that a masculine gender pervades regardless of the engagement model.

\section{Discussion and Conclusion: How the Gender Order of Forestry Affects the Opportunities for Inclusive Sustainable Forest Management}

Figure 2 is a concept map that provides an overview of the links among the concepts we have discussed in this paper. By starting at the bottom of the concept map and working our way to the top, we examined how gendered rules of entry, divisions of labour, social norms and perceptions, personal endowments and attributes, and organizational cultures result in and reinforce a particular gender order that constrains both nominal and effective participation within three engagement models for forestry management. We did this by examining the links among the different types of participation and representation and the implications of these differences for the engagement models. Despite different models or strategies, these factors remain as persistent and often invisible barriers. We argued that engagement models are embedded within a masculine gender order that severely restricts women's nominal and effective participation.

Like in forestry itself, women are distinctly underrepresented in SFM. One reviewer raised an interesting question about possible causes for this underrepresentation: "is it possible that there exists a deliberate resistance to women's involvement on the part of some actors on the basis of the likelihood that women's perceptions and concerns will challenge dominant narratives in the industry? In other words, perhaps it is not women per se who are being excluded but rather the set of values and concerns they have a propensity to hold?" Inclusiveness across a range of social groups (representing diverse values and concerns) is necessary to work toward achieving social sustainability of forests. In order to enhance inclusiveness in SFM, we need to pay attention to how women and other marginalized groups may be excluded from SFM and/or effectively participating in SFM. This requires a mix of strategies that would increase the nominal participation of women and also improve the opportunities for women to be effective. Moving beyond a simple add women and stir approach, we need to address those constraints that limit effective participation by identifying and addressing the underlying masculine gender order in forestry. Because of the link between nominal and effective participation, we need strategies that address both.

Simple practical strategies to address social constraints to SFM recognize the competing time interests of women. For example, providing an honorarium, childcare/eldercare (or costs), considering the timing of meetings recognizes time constraints. In addition, ensuring a "critical mass," 
TABLE 1: Measures to assess female participation and representation in SFM engagement models.

\begin{tabular}{|c|c|c|c|c|}
\hline \multirow{2}{*}{ Participation } & \multirow{2}{*}{$\begin{array}{l}\text { Forms of } \\
\text { Representation }\end{array}$} & \multicolumn{2}{|c|}{ SFM engagement models } & \multirow[b]{2}{*}{ Civic } \\
\hline & & Expert & Stakeholder & \\
\hline \multirow[t]{2}{*}{ Nominal } & Descriptive & $\begin{array}{l}\text { For example, numbers of } \\
\text { female "experts" }\end{array}$ & $\begin{array}{l}\text { For example, numbers of } \\
\text { female stakeholder } \\
\text { representatives and/or } \\
\text { gender issue focused } \\
\text { stakeholders }\end{array}$ & $\begin{array}{l}\text { For example, numbers of females } \\
\text { in forest advisory committees }\end{array}$ \\
\hline & Descriptive & $\begin{array}{l}\text { For example, female } \\
\text { experts are able to voice } \\
\text { their concerns in a } \\
\text { meaningful way and be } \\
\text { heard }\end{array}$ & $\begin{array}{l}\text { For example, female } \\
\text { stakeholders reps are able } \\
\text { to voice their concerns in a } \\
\text { meaningful way and be } \\
\text { heard }\end{array}$ & $\begin{array}{l}\text { For example, females are able to } \\
\text { voice their concerns in citizen } \\
\text { juries in a meaningful way and } \\
\text { be heard }\end{array}$ \\
\hline \multirow[t]{2}{*}{ Effective } & Subjective attached & $\begin{array}{l}\text { For example, experts act } \\
\text { on behalf of women } \\
\text { forestry experts whether } \\
\text { present or not }\end{array}$ & $\begin{array}{l}\text { For example, stakeholder } \\
\text { representatives act on } \\
\text { behalf of women/women's } \\
\text { groups who have a stake in } \\
\text { forestry whether present or } \\
\text { not }\end{array}$ & $\begin{array}{l}\text { For example, citizen juries act on } \\
\text { behalf of women's/women's } \\
\text { groups who have an interest in } \\
\text { forestry whether present or not }\end{array}$ \\
\hline & Objective unattached & $\begin{array}{l}\text { For example, experts } \\
\text { acting on behalf of } \\
\text { women who do not have } \\
\text { a direct stake in forestry } \\
\text { even when they are not } \\
\text { present }\end{array}$ & $\begin{array}{l}\text { For example, stakeholder } \\
\text { representatives act on } \\
\text { behalf of women's groups } \\
\text { who do not have a direct } \\
\text { stake in forestry even when } \\
\text { they are not present }\end{array}$ & $\begin{array}{l}\text { For example, citizen juries act on } \\
\text { behalf of women who do not } \\
\text { have a direct stake in forestry } \\
\text { even when they are not present }\end{array}$ \\
\hline
\end{tabular}

TABLE 2: Examples of influence of gender order on inclusivity of engagement models.

\begin{tabular}{|c|c|c|c|}
\hline \multirow{2}{*}{$\begin{array}{l}\text { Processes of gender } \\
\text { order }\end{array}$} & \multicolumn{3}{|c|}{ Engagement Models } \\
\hline & Expert (e.g., expert panels) & Stakeholder (e.g., advisory committees) & Civic (e.g., citizen juries) \\
\hline Rules of entry & $\begin{array}{l}\text { The few female experts in } \\
\text { forestry science and business } \\
\text { limit nominal participation }\end{array}$ & $\begin{array}{l}\text { Stakeholders often represent formal } \\
\text { domains limiting nominal participation } \\
\text { as women often involved in informal } \\
\text { domains considered external to forestry. }\end{array}$ & $\begin{array}{l}\text { Process of selecting citizen } \\
\text { juries contested based on } \\
\text { social norms. }\end{array}$ \\
\hline Division of labour & $\begin{array}{l}\text { Few females in senior } \\
\text { management positions limit } \\
\text { nominal participation. }\end{array}$ & $\begin{array}{l}\text { Female foresters are often assigned to } \\
\text { office-related forestry work. Women } \\
\text { often involved in community and related } \\
\text { service. }\end{array}$ & \\
\hline $\begin{array}{l}\text { Social norms \& } \\
\text { perceptions and rules } \\
\text { of practice }\end{array}$ & $\begin{array}{l}\text { Pre-existing social norms that } \\
\text { reinforce gender stereotypes } \\
\text { limits effective participation }\end{array}$ & $\begin{array}{l}\text { Perception that women do not have a } \\
\text { direct stake in forestry decisions or are } \\
\text { not qualified to represent community } \\
\text { interests. }\end{array}$ & $\begin{array}{l}\text { Citizen juries can be } \\
\text { patronizing of nonrational } \\
\text { argument. }\end{array}$ \\
\hline $\begin{array}{l}\text { Personal endowments } \\
\text { and attributes }\end{array}$ & $\begin{array}{l}\text { Stereotype that effective } \\
\text { managers require masculine } \\
\text { skills. }\end{array}$ & $\begin{array}{l}\text { Lack of critical mass may influence } \\
\text { confidence of women. }\end{array}$ & \\
\hline $\begin{array}{l}\text { Organizational } \\
\text { cultures }\end{array}$ & $\begin{array}{l}\text { Gender order within forestry } \\
\text { as a profession }\end{array}$ & Gender order within industry and society. & $\begin{array}{l}\text { Emphasis on rationalism in } \\
\text { citizen juries excludes other } \\
\text { forms of arguments }\end{array}$ \\
\hline
\end{tabular}

providing gender sensitivity training may address some of the constraints women face in actively engaging in these processes. Capturing gender differences in statistics provides essential information to acknowledge and address possible gender issues. But we recognize that these solutions focus on simplistic ideas about representation and inclusiveness. Consequently, we also advocate for more difficult changes, such as raising the profile of social sustainability alongside ecological and economic sustainability; addressing how systemic biases within forestry communities and the forest industry consider production, consumption, and appreciation of forest resources as gender-neutral; giving greater attention to how power relations affect the definition and use of local community knowledge, with particular attention to how that knowledge is produced and how participation is constrained; greater attention to strategies for incorporating the resulting diversity into SFM (e.g., gender differences across different models, such as consensus, conflict resolution, and majority wins). Greater participation in this case by women may not yield more democratic processes if we do not also have 


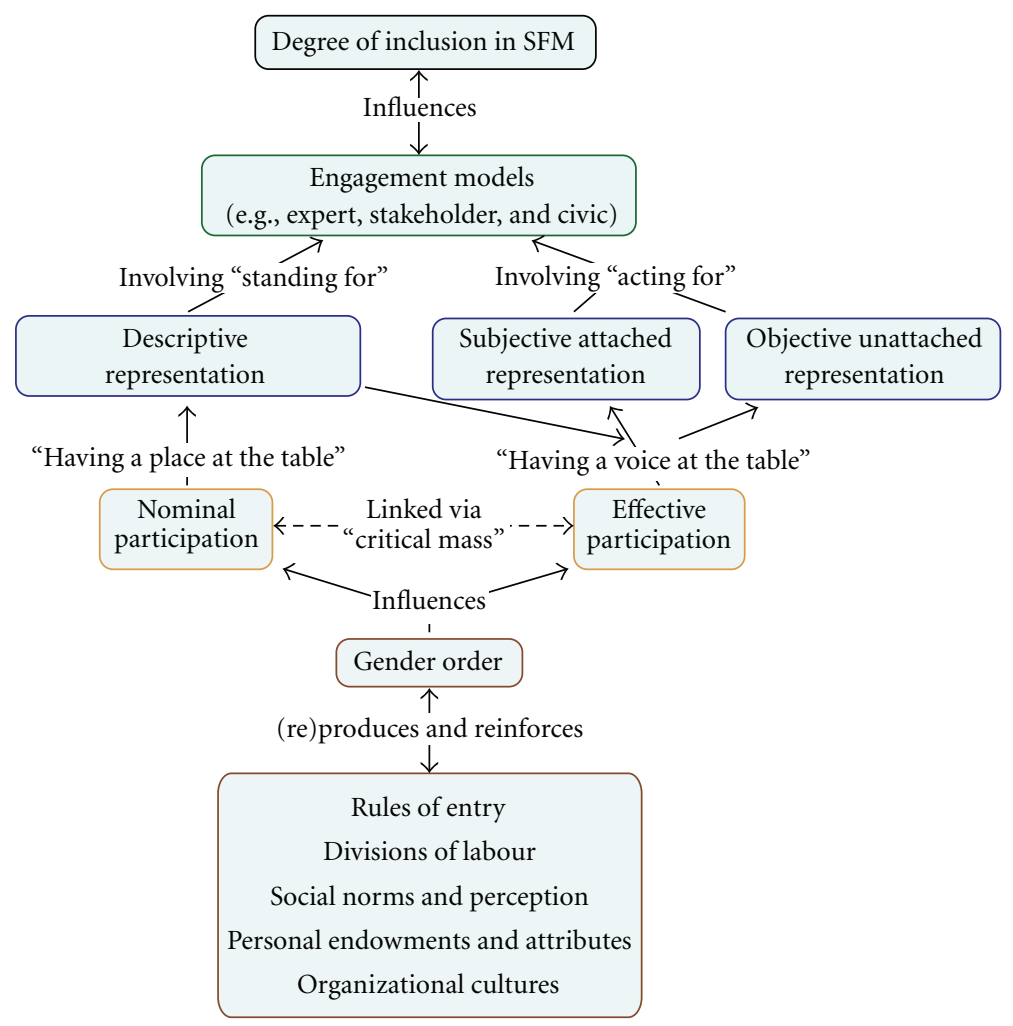

FIGURE 2: Concept map highlighting framework for considering gender order in SFM.

the right mix of participants, if we have not addressed the ground rules for debate, or if we ignore the way in which power operates at the negotiating table including how power enters speech itself. For those who are motivated to increase women's participation in forestry governance, increased awareness of the gender order and a realization that forestry does not mirror society but rather appears to be an outlier generally would also enable consideration of how other sectors have addressed some of the structural issues. One of the benefits of our meta-analysis is that we can develop "new processes" with our eyes open in advance and try to address some of the "structural" challenges rather than simply "tinker" with the engagement models hoping it will fix things.

Before closing, we acknowledge that not all women want to participate in forestry governance, just as not all men do. But those women who do want to participate may be constrained by a number of factors, including the masculine nature of direct venues as well as the organization preferences of women. As we strive to improve processes for sustainable forest management, it is important to continually increase our understanding of how our policies and daily practices construct gender. Particularly as gender positioning affects the formation and implementation of policy and has enormous influence in the differential capacity of women and men to contribute to ecological, economic, and social sustainability. A gender focus will help to sensitize researchers and policy makers to multiple inequities and help create opportunities for more inclusive concepts, analyses, and ultimately more inclusive policies and practices that place equal value on the contributions of women and men, and particular social groups without privileging any particular one. In this way, we can gain a better understanding of what constitutes inclusive forest management for all residents of forestry communities and try to identify strategies to deliver it.

While we discuss gender as a point of exclusion, we realize that the category of women is a heterogeneous one. Some groups of women are not marginalized, some groups may face forms of marginalization that are similar to other groups, while others may face a double jeopardy. For example, indigenous people and those associated with nontimber forest products have also been marginalized and may share similar forms of exclusion. Women within these social groups may experience multiple forms of exclusion from forestry management due to their gender and to the social status of their social or cultural group [61]. The exclusions can perpetuate overlapping and/or cumulative invisible losses, whereas inclusionary forest management can increase transparency and make these losses visible [62]. It is possible that the framework we have developed may apply to other marginalized or excluded groups, however, only empirical research would reveal its suitability.

\section{Acknowledgments}

The authors would like to acknowledge and thank their research participants over the years. Funds for research reported here were gratefully received from the Sustainable Forest Management Network. Students and colleagues in 
Canada and Sweden have helped hone their ideas. They also thank the anonymous reviewer for their insightful comments.

\section{References}

[1] Canadian Council of Forest Ministers (CCFM), Defining Sustainable Forest Management in Canada: criteria and Indicators 2003, Natural Resources Canada, Ottawa, Canada, 2003.

[2] G. Lidestav and M. Reed, "Preface: gender and forestry," Scandinavian Journal of Forest Research, vol. 25, no. 9, pp. 1-5, 2010.

[3] M. G. Reed, Taking Stands: gender and the Sustainability of Rural Communities, UBC Press, Vancouver, Canada, 2003.

[4] J. Varghese, P. Nelson, and R. Boehm, Towards Equal Participation: Women Foresters in Alberta, Gender and Policy Action Committee, Alberta, Canada, 1999.

[5] D. Martz, M. G. Reed, I. Brueckner, and S. Mills, Hidden Actors, Muted Voices: The Employment of Rural Women in Canadian Forestry and Agri-food Industries, Final Report to the Status of Women, Policy Research Fund, Ottawa, Ontario, 2006.

[6] M. G. Reed and K. McIlveen, "Toward a pluralistic civic science?: assessing community forestry," Society and Natural Resources, vol. 19, no. 7, pp. 591-607, 2006.

[7] J. Varghese, Impacts of, and challenges for, local ownership in the forest sector, Ph.D. Dissertation, University of Alberta, 2005.

[8] J. Varghese, Prince Albert Model Forest Public Participation Review. A report prepared for the PAMF Local Level Indicators Working Group, Saskatchewan, Canada, 2000.

[9] J. R. Parkins and D. J. Davidson, "Constructing the public sphere in compromised settings: environmental Governance in the Alberta Forest Sector," Canadian Review of Sociology, vol. 45, no. 2, pp. 177-196, 2008.

[10] K. Richardson, A. J. Sinclair, M. G. Reed, and J. R. Parkins, "Constraints to participation in Canadian forestry advisory committees: a gendered perspective," Canadian Journal of Forest Research, vol. 41, no. 3, pp. 524-532, 2011.

[11] J. R. Parkins, L. Hunt, S. Nadeau, M. Reed, J. Sinclair, and S. Wallac, "Public participation in forest management: results from a national survey of advisory committees," Information Report NOR-X-409, Northern Forestry Centre Information Report Series, 2006.

[12] M. G. Reed and J. Varghese, "Gender representation on Canadian forest sector advisory committees," Forestry Chronicle, vol. 83, no. 4, pp. 515-525, 2007.

[13] M. G. Reed, "Environmental governance and gender in canadian resource industries and communities," in Resource and Environmental Management in Canada: Addressing Conflict and Uncertainty, B. Mitchell, Ed., pp. 526-553, Oxford University Press, New York, NY, USA, 4th edition, 2010.

[14] K. D. V. Liere and R. E. Dunlap, "The social bases of environmental concern: a review of hypotheses, explanations and empirical evidence," Public Opinion Quarterly, vol. 44, no. 2, pp. 181-197, 1980.

[15] P. Mohai, "Men, women, and the environment: an examination of the gender gap in environmental concern and activism," Society \& Natural Resources, vol. 5, no. 1, pp. 1-19, 1992.

[16] D. J. Davidson and W. R. Freudenburg, "Gender and environmental risk concerns: a review and analysis of available research," Environment and Behavior, vol. 28, no. 3, pp. 302339, 1996.
[17] D. B. Tindall, "Social values and the contingent nature of public opinion and attitudes about forests," Forestry Chronicle, vol. 79, no. 3, pp. 692-705, 2003.

[18] H. Uliczka, P. Angelstam, G. Jansson, and A. Bro, "Nonindustrial private forest owners' knowledqe of and attitudes towards nature conservation," Scandinavian Journal of Forest Research, vol. 19, no. 3, pp. 274-288, 2004.

[19] D. J. Davidson, T. Williamson, and J. R. Parkins, "Understanding climate change risk and vulnerability in northern forestbased communities," Canadian Journal of Forest Research, vol. 33, no. 11, pp. 2252-2261, 2003.

[20] G. Johnsson-Latham, A Study on Gender Equality as a Prerequisite for Sustainable Development, Environment Advisory Council, Stockholm, Sweden, 2007.

[21] S. Arora-Jonsson, "Relational dynamics and strategies: men and women in a forest community in Sweden," Agriculture and Human Values, vol. 21, no. 4, pp. 355-365, 2004.

[22] K. E. Halvorsen, "Relationships between national forest system employee diversity and beliefs regarding external interest groups," Forest Science, vol. 47, no. 2, pp. 258-269, 2001.

[23] J. Seager, Earth Follies: Coming to Terms with the Global Environmental Crisis, Routledge, New York, NY, USA, 1993.

[24] D. B. Tindall, S. Davies, and C. Mauboules, "Activism and conservation behavior in an environmental movement: the contradictory effects of gender," Society and Natural Resources, vol. 16, no. 10, pp. 909-932, 2003.

[25] L. K. Ozanne, C. R. Humphrey, and P. M. Smith, "Gender, environmentalism, and interest in forest certification: Mohai's paradox revisited," Society and Natural Resources, vol. 12, no. 6, pp. 613-622, 1999.

[26] B. Livesey, "The politics of Greenpeace," Canadian Dimensions, vol. 28, pp. 7-12, 1994.

[27] S. Müller, "Report on the professional and family situation of women working in the environmental field," in Proceedings of the 2nd European Feminist Research Conference, Feminist Perspectives on Technology, Work and Ecology, T. Eberhart and C. Wachter, Eds., IFF IFZ Interdisciplinary Research Center for Technology, Work and Culture, Graz, Austria, July 1994.

[28] S. Gherardi and B. Poggio, "Creating and recreating gender order in organizations," Journal of World Business, vol. 36, no. 3, pp. 245-259, 2001.

[29] M. G. Reed, "Reproducing the gender order in Canadian forestry: the role of statistical representation," Scandinavian Journal of Forest Research, vol. 23, no. 1, pp. 78-91, 2008.

[30] T. Dunk, It's a Working Man's Town: Male Working-class Culture in Northwestern Ontario, McGill-Queen's University Press, Quebec, Canada, 1991.

[31] M. S. Carroll, Community and the Northwestern Logger: Continuities and Changes in the Era of the Spotted Owl, University of Colorado Press, Boulder, Colo, USA, 1995.

[32] B. Brandth and M. S. Haugen, "Breaking into a masculine discourse women and farm forestry," Sociologia Ruralis, vol. 38, no. 3, pp. 427-442, 1998.

[33] B. Brandth and M. S. Haugen, "From lumberjack to business manager: masculinity in the Norwegian forestry press," Journal of Rural Studies, vol. 16, no. 3, pp. 343-355, 2000.

[34] UNECE/FAO Team of Specialists on Gender and Forestry, Ed., Time for Action: Changing the Gender Situation in Forestry Report, Food and Agriculture Organization of the United Nations, Rome, Italy, 2006.

[35] J. K. Gibson-Graham, "Stuffed if I know!: reflections on postmodern feminist social research, Gender," Place and Culture, vol. 1, no. 2, pp. 205-224, 1994. 
[36] V. Preston, D. Rose, G. Norcliffe, and J. Holmes, "Shift work, childcare and domestic work: divisions of labour in Canadian paper mill communities," Gender, Place and Culture, vol. 7, no. 1, pp. 5-29, 2000.

[37] A. Sinclair, Trials at the Top, The Australian Centre, University of Melbourne, Melbourne, Australia, 1994.

[38] P. Davidson and R. Black, "Women in natural resources management: finding a more balanced perspective," Society and Natural Resources, vol. 14, no. 8, pp. 645-656, 2001.

[39] B. Brandth, G. Follo, and M. S. Haugen, "Women in forestry: dilemmas of a separate women's organization," Scandinavian Journal of Forest Research, vol. 19, no. 5, pp. 466-472, 2004.

[40] WinSETT Centre, "QuickStats \# 11: Women in Paid Work," 2011, http://www.ccwestt.org/Portals/0/publications/QuickStatsNo11\%20Jul\%202011.pdf.

[41] J. R. Parkins and R. E. Mitchell, "Public participation as public debate: a deliberative turn in natural resource management," Society and Natural Resources, vol. 18, no. 6, pp. 529-540, 2005.

[42] A. M. Wellstead, R. C. Stedman, and J. R. Parkins, "Understanding the concept of representation within the context of local forest management decision making," Forest Policy and Economics, vol. 5, no. 1, pp. 1-11, 2003.

[43] H. Pitken, The Concept of Representation, University of California Press, Berkeley, Calif, USA, 1967.

[44] A. Conley and M. A. Moote, "Evaluating collaborative natural resource management," Society and Natural Resources, vol. 16, no. 5, pp. 371-386, 2003.

[45] M. Alston and J. Wilkinson, "Australian farm women—shut out or fenced in? The lack of women in agricultural leadership," Sociologia Ruralis, vol. 38, no. 3, pp. 391-408, 1998.

[46] B. Agarwal, "Participatory exclusions, community forestry, and gender: an analysis for South Asia and a conceptual framework," World Development, vol. 29, no. 10, pp. 1623$1648,2001$.

[47] D. Dahlerup, "From a small to a large majority: women in Scandinavian Politics," Scandinavian Political Studies, vol. 11, pp. 275-298, 1988.

[48] E. Teske and B. Beedle, "Journey to the top-breaking through the canopy: Canadian experiences," Forestry Chronicle, vol. 77, no. 5, pp. 846-853, 2001.

[49] M. Fullerton, "Gender structures in forestry organizations: Canada," in Time for Action: Changing the Gender Situation in Forestry, UNECE/FAO Team of Specialists on Gender and Forestry, Ed., p. 2026, Food and Agriculture Organization of the United Nations, Rome, Italy, 2006.

[50] S. McGregor, Beyond Mothering Earth: Ecological Citizenship and the Politics of Care, UBC Press, Vancouver, Canada, 2006.

[51] S. Gherardi, Gender, Symbolism and Organizational Cultures, Sage, London, Uk, 1995.

[52] University of Newcastle upon Tyne. "Citizens" Jury calls for moratorium on commercialisation of GM to continue University of Newcastle upon Tyne, 2005, http://www.ncl.ac.uk/press .office/press.release/content.phtml?ref=1063031063.

[53] G. Smith and C. Wales, "The theory and practice of citizens' juries," Policy and Politics, vol. 27, no. 3, pp. 295-308, 1999.

[54] Jefferson Center, "Citizen Jury Handbook," 2005, http://www .jefferson-center.org/.

[55] M. P. Pimbert and W. T. Prajateerpu, A Citizens Jury/Scenario Workshop on Food and Farming Futures for Andhra Pradesh, India, International Institute for Environment and Development, London, UK, 2002.

[56] N. Kanji and S. F. Tan, "Understanding local difference: gender (plus) matters for NGOs," Participatory Learning and Action, vol. 58, no. 1, pp. 74-81, 2008.
[57] J. Gobert, Justice Democracy and the Jury, Ashgate Publishing Company, Aldershot, UK, 1997.

[58] A. Coote and J. Lenaghan, Citizens' Juries: Theory into Practice, IPPR, London, UK, 1997.

[59] H. Ward, A. Norval, T. Landman, and J. Pretty, “Open citizens' juries and the politics of sustainability," Political Studies, vol. 51, no. 2, pp. 282-299, 2003.

[60] S. Pickard, "Citizenship and consumerism in health care: a critique of citizens' juries," Social Policy and Administration, vol. 32, no. 3, pp. 226-244, 1998.

[61] M. G. Reed and D. Davidson, "Terms of Engagement: the involvement of Canadian rural communities in sustainable forest management," in Reshaping Gender and Class in Rural Spaces, B. Pini and B. Leach, Eds., pp. 199-220, Ashgate Publishing Company, Aldershot, UK, 2011.

[62] N. J. Turner, R. Gregory, C. Brooks, L. Failing, and T. Satterfield, "From invisibility to transparency: identifying the implications," Ecology and Society, vol. 13, no. 2, article 7, 2008. 

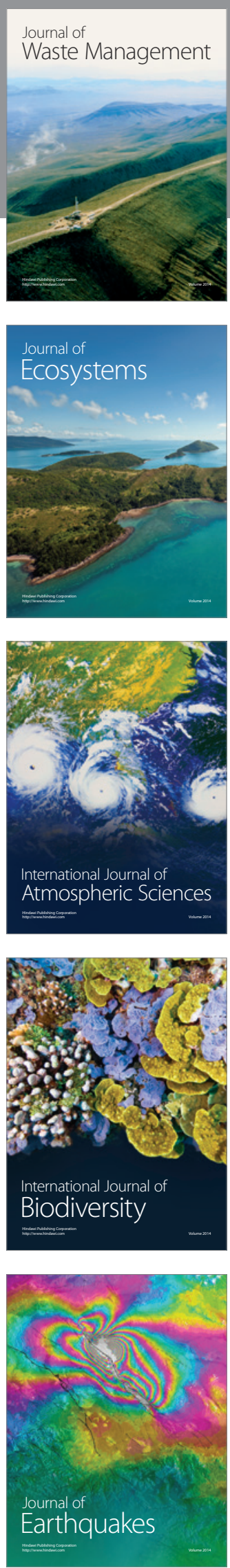
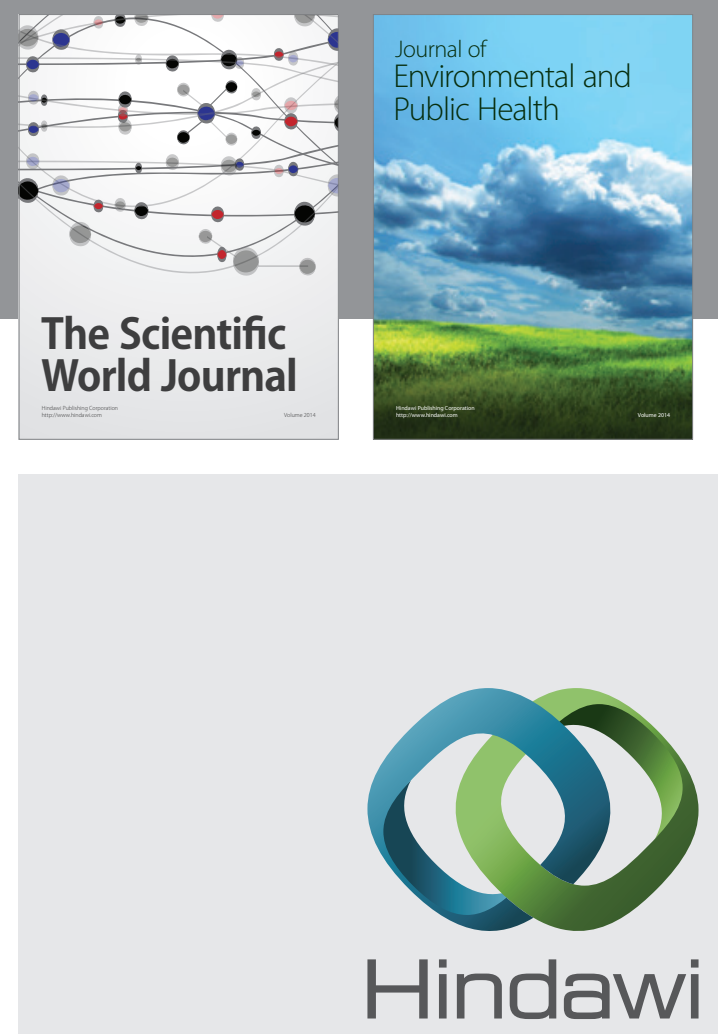

Submit your manuscripts at

http://www.hindawi.com
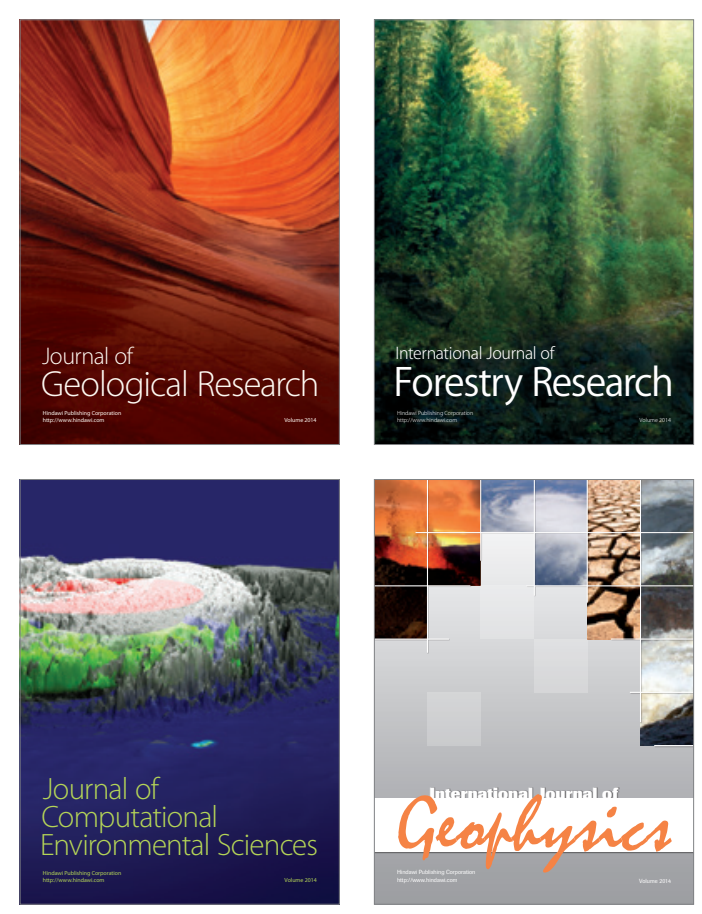
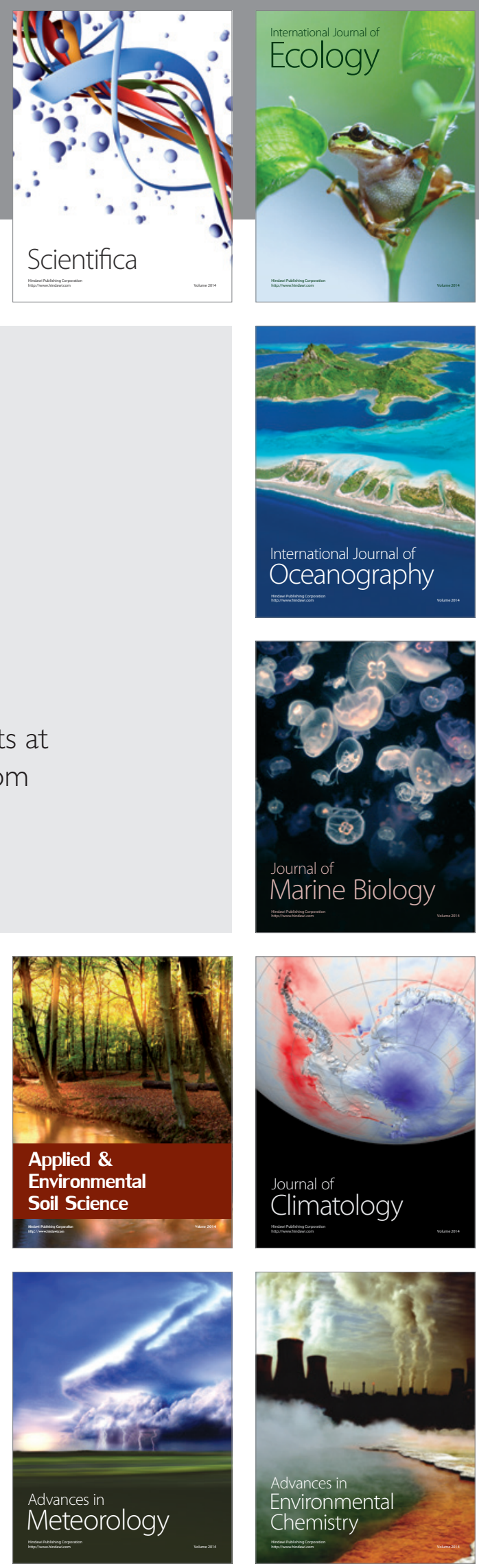